\title{
Anatomic reconstruction or temporary screw stabilization of chronic symptomatic anterolateral proximal tibiofibular joint instability
}

\author{
Michel P. J. van den Bekerom • Adam Weir • \\ Rudolf E. van der Flier
}

Received: 30 November 2010/ Accepted: 1 February 2011/Published online: 19 February 2011

(C) The Author(s) 2011. This article is published with open access at Springerlink.com

Dear Editors,

We read with great interest the recent article of Horst and Laprade "Anatomic reconstruction of chronic symptomatic anterolateral proximal tibiofibular joint instability" [2]. The authors are to be complemented on a well-written and well-illustrated report of an operative technique with good results in two cases. The authors conclude that an anatomic reconstruction of the proximal posterior tibiofibular joint may be considered for patients with chronic, symptomatic proximal tibiofibular joint anterolateral subluxation. We would like to place some remarks that we feel should be discussed before accepting the above-mentioned conclusion.

1. We will emphasize as already mentioned by the authors that there are 4 different types of instability, and the most frequent type $(67 \%)$ is the anterolateral dislocation [4]. This type is mostly caused by a hyperflexion trauma of the knee with plantar flexion and inversion of the foot. In this type of injury, there is a rupture of the posterior and anterior capsular ligament and there could also be an injury of the lateral collateral ligament. These are the main

M. P. J. van den Bekerom ( $\square)$

Department of Orthopaedic Surgery,

Academic Medical Center, Meibergdreef 15,

P.O. Box 22660, 1105 AZ Amsterdam, The Netherlands

e-mail: Bekerom@gmail.com

\section{A. Weir}

Department of Sports Medicine, MCH Antoniushove,

Burg Banninglaan 1, 2262 BA Leidschendam, The Netherlands

R. E. van der Flier

Department of Orthopaedic Surgery, MCH Antoniushove,

Burg Banninglaan 1, 2262 BA Leidschendam, The Netherlands stabilizers of the tibiofibular joint. Ogden identified two variants of the proximal tibiofibular joint, horizontal (coronal plane) and oblique configurations [4, 5]. The horizontal proximal tibiofibular joint lies in the coronal plane and, with a larger articular surface and greater mobility, is more flexible and theoretically more resistant to rotational forces tending to cause fibular dislocation $[4,5]$.

2. Peroneal nerve and ankle injuries can occur concomitantly with anterolateral proximal tibiofibular dislocation [10]. Evaluation of the distal syndesmotic ligaments and the interosseous membrane is advisable because the mechanism of trauma can cause a disruption of the distal tibiofibular syndesmosis [3, 10]. In cases of syndesmotic instability, prompt stabilization of the distal tibiofibular joint is advocated [10]. An associated transient peroneal palsy is commonly seen in types II, III, and IV [7, 10]. In more rare cases, disorders at the proximal tibiofibular joint can be a possible cause of referred pain proximally [9].

3. In the two cases described, 3 months of physical therapy with an emphasis on knee strengthening was ineffective. We would suggest that 6 months is a more appropriate duration of non-operative treatment. We also think there are more non-operative options for patients with chronic instability which can be considered like modifications of a patient's activity level and training programs, utilization of a supportive strap, lower leg strengthening, and modifications in the lower kinetic chain biomechanics [6]. A supportive strap placed $1 \mathrm{~cm}$ below the fibular head can offer relief in many cases. Care should be taken not to apply the strap too tightly or for too long, as this could cause peroneal nerve palsy. The strap should be worn during activities 
that cause the symptoms [6-8]. Strengthening exercises should consist of:

a. Strengthening of lateral and rotational stability and coordination on a balancing disk or a trampoline.

b. Stretching exercises for $\mathrm{m}$. biceps femoris, m. soleus, and $\mathrm{m}$. gastrocnemius.

c. Strengthening exercises of the peroneal muscles with a dynaband. The affected foot is moved in eversion against the resistance of the band. It is important to avoid activities involving hyperflexion of the knee [1, 6].

4. We agree with the authors that the ideal treatment for patients requiring surgical intervention has not been well defined. As this is a rare problem, there is a lack of data and no large series are available concerning the outcome of the different treatment possibilities [5]. The reader should also be aware of the technique described in our previous article using screw fixation [8]. The advantage of this technique is that it is much less invasive and less extensive and requires only a minimal incision compared to the technique of the Horst and LaPrade [2] and other ligament reconstructions. For all techniques described, the preliminary results are good, but the surgery is technically demanding, with large incisions and extensive soft tissue dissection and the risk of damaging the common peroneal nerve [10]. We performed a temporary screw fixation (3-6 months) of the proximal tibiofibular joint and a release of the peroneal nerve. In general, the results in our series ( $>10$ athletes) performing this "more simple" technique are good. The disadvantage of this technique is the need for screw removal as it is known that arthrodesis of the proximal tibiofibular joint causes increased rotational forces in the ankle and often leads to pain and instability of the ankle joint $[4,5]$.

In summary, we agree with Horst and Laprade that an anatomic reconstruction of the proximal posterior tibiofibular joint may be considered for patients with chronic, symptomatic proximal tibiofibular joint anterolateral subluxation, but we think there are other less extensive alternative surgical options. A comparative study should answer this last question. We would be interested to further discuss this with the authors.

Open Access This article is distributed under the terms of the Creative Commons Attribution Noncommercial License which permits any noncommercial use, distribution, and reproduction in any medium, provided the original author(s) and source are credited.

\section{References}

1. Halbrecht JL, Jackson DW (1991) Recurrent dislocation of the proximal tibiofibular joint. Orthop Rev 20:957-960

2. Horst PK, LaPrade RF (2010) Anatomic reconstruction of chronic symptomatic anterolateral proximal tibiofibular joint instability. Knee Surg Sports Traumatol Arthrosc 18:1452-1455

3. Levy BA, Vogt KJ, Herrera DA, Cole PA (2004) Maisonneuve fracture equivalent with proximal tibiofibular dislocation. J Bone Joint Surg Am 88:1111-1116

4. Ogden JA (1974) Subluxation and dislocation of the proximal tibiofibular joint. J Bone Joint Surg Am 56:145-154

5. Ogden JA (1974) Anatomy and function of the proximal tibiofibular joint. Clin Orthop 101:186-191

6. Semonian RH, Denlinger PM, Duggan RJ (1995) Proximal tibiofibular subluxation relationship to lateral knee pain: a review of proximal tibiofibular joint pathologies. J Orthop Sports Phys Ther 21:248-257

7. Sijbrandij S (1978) Instability of the proximal tibiofibular joint. Acta Orthop Scand 49:621-626

8. Van den Bekerom MP, Weir A, van der Flier RE (2004) Surgical stabilisation of the proximal tibiofibular joint using temporary fixation: a technical note. Acta Orthop Belg 70:604-608

9. van Ooij B, van Ooij A, Morrenhof JW, van Dijk CN (2011) Proximal tibiofibular synostosis as a possible cause of a pseudoradicular syndrome: a case report. Knee Surg Sports Traumatol Arthrosc Jan 11. doi: 10.1007/s00167-010-1379-7

10. Van Seymortier P, Ryckaert A, Verdonk P, Almqvist KF, Verdonk R (2008) Traumatic proximal tibiofibular dislocation. Am J Sports Med 36:793-798 